\title{
THERAPEUTIC NUCLEAR MEDICINE
}

\section{Radiopharmaceutical Treatment of Malignant Pheochromocytoma}

James C. Sisson, Brahm Shapiro, William H. Beierwaltes, Jerry V. Glowniak, Masayuki Nakajo, Thomas J. Mangner, James E. Carey, Dennis P. Swanson, Jean E. Copp, Winston G. Satterlee, and Donald M. Wieland

\section{The University of Michigan Medical Center, Ann Arbor, Michigan}

Apart from relieving effects of secreted catecholamines, treatments of malignant pheochromocytoma have achieved little success. When the radiopharmaceutical, meta-[ $\left.{ }^{131} 1\right]$ iodobenzylguanidine (I-131 MIBG), was found to concentrate in some malignant pheochromocytomas, we calculated that this agent could impart therapeutic doses of radiation to these tumors. We therefore treated five patients with two to four doses of I-131 MIBG prepared in high specific activity, 8-11 Cl/mmol. Individual doses were given at 3- to 10-mo intervals and in 97- to 197-mCi amounts. Two patients exhibited subjective and objective benefits. Their tumors declined in size (to $28 \%$ and $30 \%$ of original volumes) and in hormone secretion (to $50 \%$ or less of baseline rates). The other three patients manifested few symptoms before treatment and showed few or no objective improvement afterward. The tumors of the patients who responded to I-131 MIBG (a) appeared to be more rapidly growing, (b) recelved more cumulative rads, and (c) were more predominantly in soft tissues (in contrast to bone) than those in the patients who obtained little benefit. No toxic effects were encountered during the treatments, and only minor and temporary untoward responses were seen later.

J Nucl Med 24: 197-206, 1984

Despite the applications of newer tumor treatments, malignant pheochromocytomas grow and spread inexorably. The ravages of the excessive catecholamines produced by these cancers can be prevented or lessened by metyrosine, which impairs synthesis, or by agents such as phenoxybenzamine, which block effects of the hormone $(1,2)$. However, such treatments do not affect tumor growth. Moreover, progression of the neoplasms has been slowed little (3-5), and often not at all (2$4,6,7)$, by external beam irradiation and a variety of chemotherapeutic drugs. If not completely excised by the surgeon, malignant pheochromocytomas advance relentlessly.

When the radiopharmaceutical, ${ }^{131} \mathrm{I}$-meta-[131I]iodobenzylguanidine (I-131 MIBG, Fig. 1) was found

Received June 3, 1983; revision accepted July 25, 1983.

For reprints contact: James C. Sisson, MD, Nuclear Medicine Division, University of Michigan Medical Center, Ann Arbor, MI 48109. to concentrate in benign or malignant pheochromocytomas $(8)$, we recognized that this agent might deliver irradiation selectively to unresectable tumors and in larger doses than by previous methods. We therefore treated five patients who manifested varied patterns of recurrent malignant pheochromocytoma, using I-131 MIBG of high specific activity. Two to four doses of I-131 MIBG imparted 3,500-19,800 rad to the neoplasms. The responses to this new therapy are reported here.

\section{MATERIALS AND METHODS}

Patients. One or more tumors that were histologically typical of pheochromocytoma had been removed from each patient; de-differentiation of histology was not seen in any tumor. Recurrences of tumor were in locations not considered to be sites of benign pheochromocytomas: lymph node, liver, and bone.

Table 1 lists demographic and clinical data for the five 


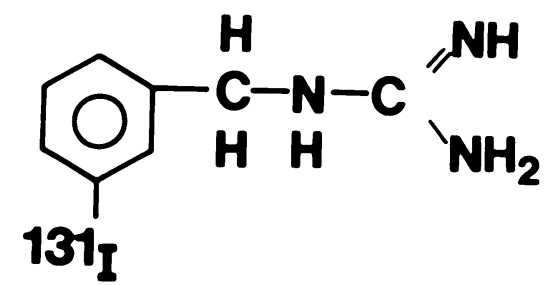

FIG. 1. Molecular structure of meta-[ ${ }^{131}$ ] iodobenzylguanidine.

patients. Each required medication to lower blood pressure and/or to protect against recurrent spells of symptoms. Patients 1 and 2 were older, and these two individuals suffered more severe symptoms and disability than the younger three patients. Indeed, the crescendo of symptoms in Patients 1 and 2 were alarming. In contrast, drug therapy eliminated almost all complaints from Patients 3 and 4 over a number of years. For $\mathrm{Pa}$ tient 5 , the disease had been recognized for only a year, and he, too, was without symptoms.

Patients 1 and 2 exhibited tumors predominately located in soft tissues: retroperitoneum and liver, respectively (Table 2). Lungs and abdomen, but also many bones, were sites of metastases in Patient 3. Bony deposits of neoplasm characterized the pattern of dissemination in Patients 4 and 5. Since sequential radiographs and computed tomograms were lacking for Patients 2, 4 , and 5 , growth rates of tumors in the pretherapy period could not be charted for them. However, before I-131 MIBG was given to Patient 1, computerized tomography portrayed a doubling of the volume of his largest tumor over 10 mo. At the other end of the spectrum was Patient 3 , in whom radiographs over $4 \mathrm{yr}$ depicted no change in the dimensions of the lung and skull metastases.

Only Patient 3 was cared for at this center for much of his illness; the other patients were referred from other medical centers for treatment. In the years preceding therapy with I-131 MIBG, the evolution of tumor secretions could not be reliably determined since assays for catecholamine and catecholamine metabolites in the urines differed in different laboratories, and measurements of plasma norepinephrine have only recently been developed.

Methods. Concentrations of catecholamines in plasma were measured by a radioenzymatic assay $(9,10)$ from blood drawn in the fasting state, during quiet recumbency, and after a butterfly needle had been in place for $30 \mathrm{~min}$. Excretion rates of catecholamines, normetanephrine, metanephrine, and vanillylmandelic acid (VMA) were determined by the method of von Euler and Lishajko $(11,12)$.

The enzyme, phenylethanolamine- $\mathrm{N}$-methyltransferase, converts norepinephrine to epinephrine; to work efficiently, the enzyme requires levels of cortisol found only in the proximity of the adrenal cortex (13). Malignant pheochromocytomas, which generally reside in sites remote from the adrenal cortex, produce relatively little epinephrine. However, despite an inefficient enzyme system, measurable amounts of epinephrine could be produced from the enormous quantities of norepinephrine synthesized by some pheochromocytomas; the

TABle 1. Clinical fEATURES OF PATIENTS WITH METASTATIC PHEOChROMOCytOMA

\begin{tabular}{|c|c|c|c|c|c|c|}
\hline Patient & $\begin{array}{l}\text { Age } \\
\text { (yr) }\end{array}$ & Sex & Major symptoms & $\begin{array}{l}\text { Blood pressure during } \\
\text { drug } R x\end{array}$ & Drugs & $\begin{array}{l}\text { Status before } 1-131 \\
\text { MIBG Rx }\end{array}$ \\
\hline 1 & 61 & $M$ & $\begin{array}{l}\text { Chronic abdominal pain; } \\
\text { recurrent episodes of } \\
\text { small-bowel obstruction }\end{array}$ & $\begin{array}{l}\text { labile; often normal } \\
\text { systolic: } 120-190 \\
\text { diastolic: } 70-105\end{array}$ & $\begin{array}{l}\text { Phenoxybenzamine } \\
40 \mathrm{mg} / \mathrm{d} \\
\text { Carbamazepine } \\
200 \mathrm{mg} / \mathrm{d}\end{array}$ & $\begin{array}{l}\text { Progressing symp- } \\
\text { toms over } 2 \text { yr }\end{array}$ \\
\hline 2 & 66 & $F$ & $\begin{array}{l}\text { Pain in legs; weak and } \\
\text { able to walk only } \\
\text { a few steps }\end{array}$ & $\begin{array}{l}\text { systolic: } 145-180 \\
\text { diastolic: } 70-105\end{array}$ & $\begin{array}{l}\text { Metyrosine } 500 \mathrm{mg} / \mathrm{d} \\
\text { Carbidopa } 25 \mathrm{mg} / \mathrm{d} \\
\text { Levodopa } 200 \mathrm{mg} / \mathrm{d} \\
\text { Thyroid extract } \\
180 \mathrm{mg} / \mathrm{d}\end{array}$ & $\begin{array}{l}\text { Progressing symp- } \\
\text { toms over } 1 \mathrm{yr}\end{array}$ \\
\hline 3 & 26 & $M$ & $\begin{array}{l}\text { Palpable tumor in skull; } \\
\text { headaches and sweating } \\
\text { controlled by medication }\end{array}$ & $\begin{array}{l}\text { systolic: } 160-180 \\
\text { diastolic: } 90-120\end{array}$ & $\begin{array}{l}\text { Phenoxybenzamine } \\
180 \mathrm{mg} / \mathrm{d} \\
\text { propranolol } 120 \mathrm{mg} / \mathrm{d} \\
\text { hydralazine } 75 \mathrm{mg} / \mathrm{d}\end{array}$ & $\begin{array}{l}\text { No progression in } \\
6 \mathrm{yr}\end{array}$ \\
\hline 4 & 33 & $\mathbf{M}$ & $\begin{array}{l}\text { Episodes of headache, } \\
\text { palpitations, sweating } \\
\text { that are controlled by } \\
\text { medication }\end{array}$ & $\begin{array}{l}\text { labile; } \\
\text { systolic: } 130-160 \\
\text { diastolic: } 90-100\end{array}$ & $\begin{array}{l}\text { Phenoxybenzamine } \\
40 \mathrm{mg} / \mathrm{d} \\
\text { propranolol } 80 \mathrm{mg} / \mathrm{d} \\
\text { diazepam } 15 \mathrm{mg} / \mathrm{d}\end{array}$ & Stable for $2 \mathrm{yr}$ \\
\hline 5 & 15 & $\mathbf{M}$ & $\begin{array}{l}\text { Palpable tumor; pain in } \\
\text { back when vertebra } \\
\text { collapsed from metastasis }\end{array}$ & $\begin{array}{l}\text { systolic: } 160-180 \\
\text { diastolic: } 80-100\end{array}$ & $\begin{array}{l}\text { Phenoxybenzamine } \\
30 \mathrm{mg} / \mathrm{d} \\
\text { propranolol } \\
20 \mathrm{mg} / \mathrm{d}\end{array}$ & $\begin{array}{l}\text { Large tumor removed } \\
\text { from abdomen } \\
6 \text { mo before; no } \\
\text { other symptoms }\end{array}$ \\
\hline
\end{tabular}




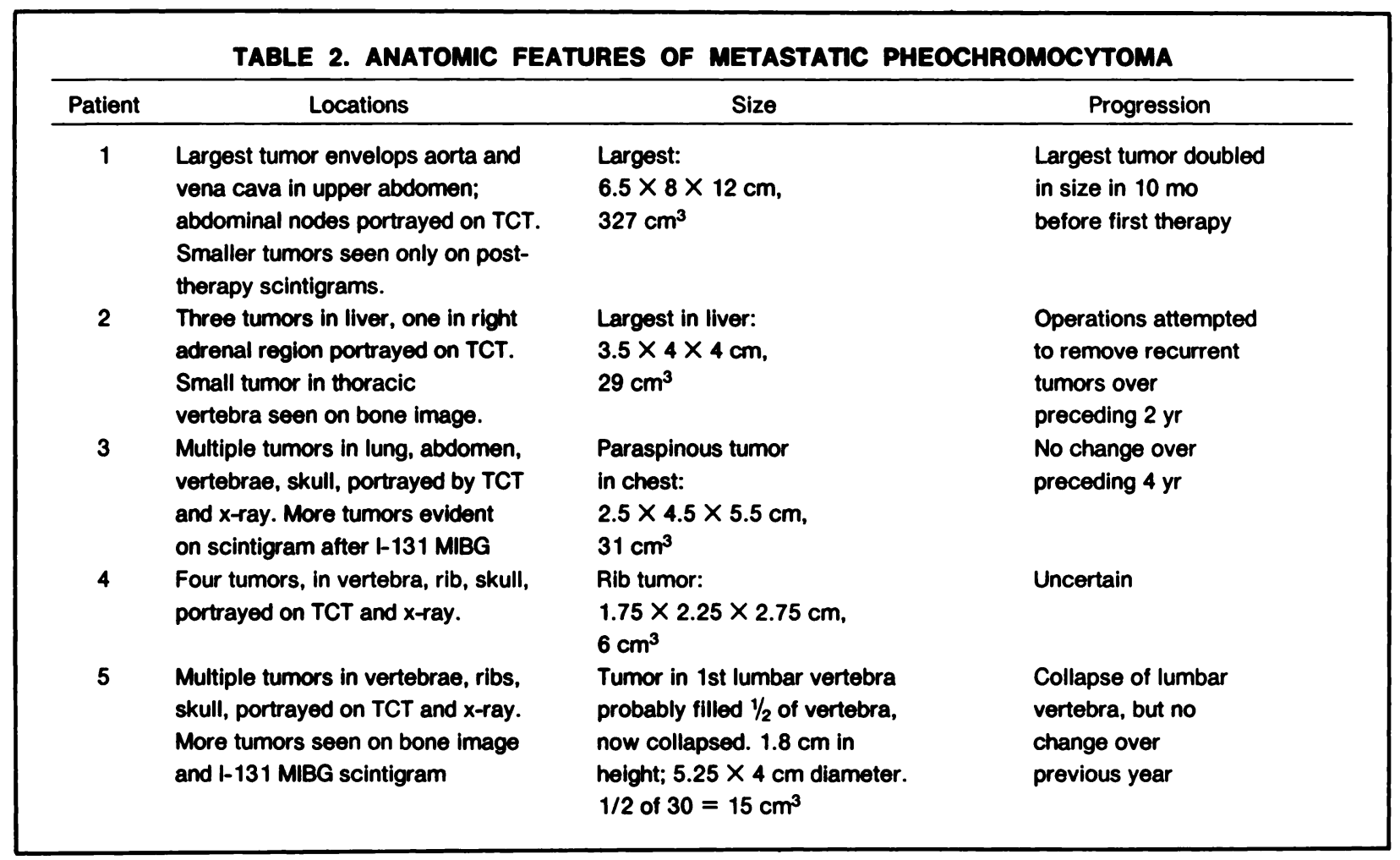

epinephrine could be synthesized in the tumor, but also in other tissues (14). Moreover, the techniques of assay may not completely separate epinephrine from norepinephrine, and some of the epinephrine reported may actually be norepinephrine. In our patients, plasma levels and the urinary rates of excretion of epinephrine were, as expected, relatively low compared with those of norepinephrine. Some of the epinephrine in the patients was probably derived from their adrenal medullas, the normal source of this hormone. How much epinephrine was derived from the pheochromocytomas is uncertain, but in any case, the contributions of epinephrine to the overall catecholamine pictures must have been minor. Therefore, values for epinephrine and its metabolite, metanephrine, are omitted from the tables.

Scintigraphy was performed as previously described (8). Briefly, $0.5 \mathrm{mCi}$ of I-131 MIBG with specific activity of $1.3 \mathrm{Ci} / \mathrm{mmol}$ was injected intravenously for tracer studies. Scintigrams were produced with a gamma camera using a high-energy, parallel-hole collimator. The images were overlapping from the level of the urinary bladder through the patient's skull. For the earlier treatments, thyroidal uptake was blocked by the administration of Lugol's iodine solution, three drops twice a day ( $~ 50 \mathrm{mg}$ of iodine), and for later treatments by a saturated solution of potassium iodide, one drop three times a day ( $\sim 150 \mathrm{mg}$ of iodine). Patients started the iodide medication a day before the injection of tracer I-131 MIBG, and ending a month after the treatment. Tracer studies were carried out over $1 \mathrm{wk}$. Excretion of I-131 was measured for at least 4 days after the tracer dose. Tracer I-131 MIBG was excreted at about $40 \%$ of dose at $24 \mathrm{hr}$, and $65-70 \%$ at $72 \mathrm{hr}$ by each patient. These values were similar to those previously determined in normal volunteers (15). Excretion rates of therapeutic quantities of I-131 MIBG were measured in several patients, and did not differ from those of the tracer studies. Total-body irradiation was calculated to be less than $45 \mathrm{rad}$ at the highest dose of I-131 MIBG (197 $\mathrm{mCi})$.

Computerized tomography sections of $1 \mathrm{~cm}$, and occasionally of $0.5 \mathrm{~cm}$, were made through representative tumors that corresponded to those seen on scintigrams. Tumors were considered to be ellipsoid in configuration for calculations of volume, except in Patient 5, where a cylindrical pattern was seen in a vertebra. Rad dosage was calculated (16) for selected tumors in each patient after measurements were made of: (a) volume, (b) fractional dose uptake at $24 \mathrm{hr}$ (assumed, from tracer studies, to approach maximum at $25 \mathrm{hr}$ ) by conjugate views, and (c) biologic half-life $(17,18)$ (Table 3). Some variability appeared in tumor concentration of I-131 MIBG among tumors within a patient, especially in Patients 3-5.

For therapy, I-131 MIBG was prepared, at specific activity six to eight times that of the tracer material, by way of an exchange technique, facilitated by ammonium sulfate, a method that yielded $45 \%$ of the radioactivity as product at $8-11 \mathrm{Ci} / \mathrm{mmol}(19)$. The therapeutic doses of $30 \mathrm{ml}$ were infused intravenously over $90 \mathrm{~min}$, with rates of infusion controlled by a pump. Heart rate, blood pressure, and ECG pattern were continuously monitored 
TABLE 3. RADIATION DOSE CALCULATION

\begin{tabular}{|c|c|c|c|c|c|c|}
\hline \multirow[b]{2}{*}{ Patient } & \multirow[b]{2}{*}{$\begin{array}{l}\text { Rx } \\
\text { No. }\end{array}$} & \multirow[b]{2}{*}{$\begin{array}{l}\text { Dose } \\
\text { (mCi) }\end{array}$} & \multirow[b]{2}{*}{$\begin{array}{c}\text { Volume } \\
\left(\mathrm{cm}^{3}\right)\end{array}$} & \multicolumn{2}{|l|}{ Tumor indices } & \multirow[b]{2}{*}{$\operatorname{Rad}$} \\
\hline & & & & $\begin{array}{c}\text { Fraction of } \\
\text { administered dose } \\
\text { in tumor at } 24 \mathrm{hr}\end{array}$ & $\begin{array}{l}\text { Effective } \\
\text { l-131 } t_{1 / 2} \\
\text { (days) } \\
\end{array}$ & \\
\hline \multirow[t]{7}{*}{1} & 1 & 97 & 327 & 0.55 & 3.0 & 8000 \\
\hline & & & (abdominal) & & & \\
\hline & 2 & 99 & 251 & 0.45 & 2.0 & 5980 \\
\hline & 3 & 135 & 236 & 0.15 & 1.6 & 2540 \\
\hline & 4 & 153 & 141 & 0.12 & 1.3 & 3270 \\
\hline & Total & $\overline{484}$ & & & & $\overline{19,790}$ \\
\hline & & (15 mo) & & & & \\
\hline \multirow[t]{6}{*}{2} & 1 & 100 & 29 & 0.014 & 1.6 & 1490 \\
\hline & & & (liver) & & & \\
\hline & 2 & 100 & not measured * & $0.025^{\dagger}$ & $1.6^{\dagger}$ & $2650^{\dagger}$ \\
\hline & 3 & 173 & 17 & 0.025 & 2.8 & 11,540 \\
\hline & Total & $\overline{373}$ & & & & \\
\hline & & (8 mo) & & & & $\overline{15,680}$ \\
\hline \multirow[t]{6}{*}{3} & 1 & 103 & 31 & 0.011 & 3.1 & 1570 \\
\hline & & & (thorax) & & & \\
\hline & 2 & 110 & no change & $0.011^{\dagger}$ & $3.1^{\dagger}$ & $1680^{\dagger}$ \\
\hline & 3 & 197 & no change & 0.011 & 3.7 & 3760 \\
\hline & Total & $\overline{410}$ & & & & $\overline{7010}$ \\
\hline & & (17 mo) & & & & \\
\hline \multirow[t]{5}{*}{4} & 1 & 97 & 6 & $0.008^{\dagger}$ & $0.65^{\dagger}$ & $1260^{\dagger}$ \\
\hline & & & rib & & & \\
\hline & 2 & 173 & no change & $0.008^{\dagger}$ & $0.65^{\dagger}$ & $2250^{\dagger}$ \\
\hline & Total & $\overline{270}$ & & & & $\overline{3510}$ \\
\hline & & (3 mo) & & & & \\
\hline \multirow[t]{5}{*}{5} & 1 & 106 & 20 & $0.022^{\dagger}$ & $1.6^{\dagger}$ & $4550^{\dagger}$ \\
\hline & & & (lumbar vertebra) & & & \\
\hline & 2 & 187 & not measured* & 0.022 & 1.6 & 8020 \\
\hline & Total & 293 & & & & $\overline{12,570}$ \\
\hline & & (3 mo) & & & & \\
\hline
\end{tabular}

during infusion and for 18-24 hr afterward. Repeat treatments were given within 3 to 5 mo-except for Patient 3, in whom 7 and 10 mo elapsed between doses.

\section{RESULTS}

Changes in the malignant pheochromocytomas. $\mathrm{Pa}$ tients were evaluated three or more months after each treatment with I-131 MIBG. Responses to the therapy are summarized in Table 4. Patients 1 and 2 exhibited distinct benefits that persist to date, and for over $1 \mathrm{yr}$. In both patients symptoms disappeared, accompanied by objective changes: reduction in volume and function of the tumors to less than $50 \%$ of pretreatment values.
The function of the tumors in Patient 1 was manifest, in the absence of symptoms, by a markedly high rate of excretion of normetanephrine and borderline-high rate of excretion of VMA; norepinephrine values in his plasma and urine were generally normal. Therefore, he required no medication when his recurrent symptoms disappeared along with his chronic pain. The uptake of I-131 MIBG by his tumor progressively declined after each treatment (Fig. 2)-more so than the reduction in volume of his neoplasm (Fig. 3). Metastases in chest and neck, seen only as scintigrams after his first treatment, could not be detected after his second and third treatment doses. Thus, for Patient 1, rad dosage became less in subsequent treatments, even though his third and fourth doses contained more millicuries. 


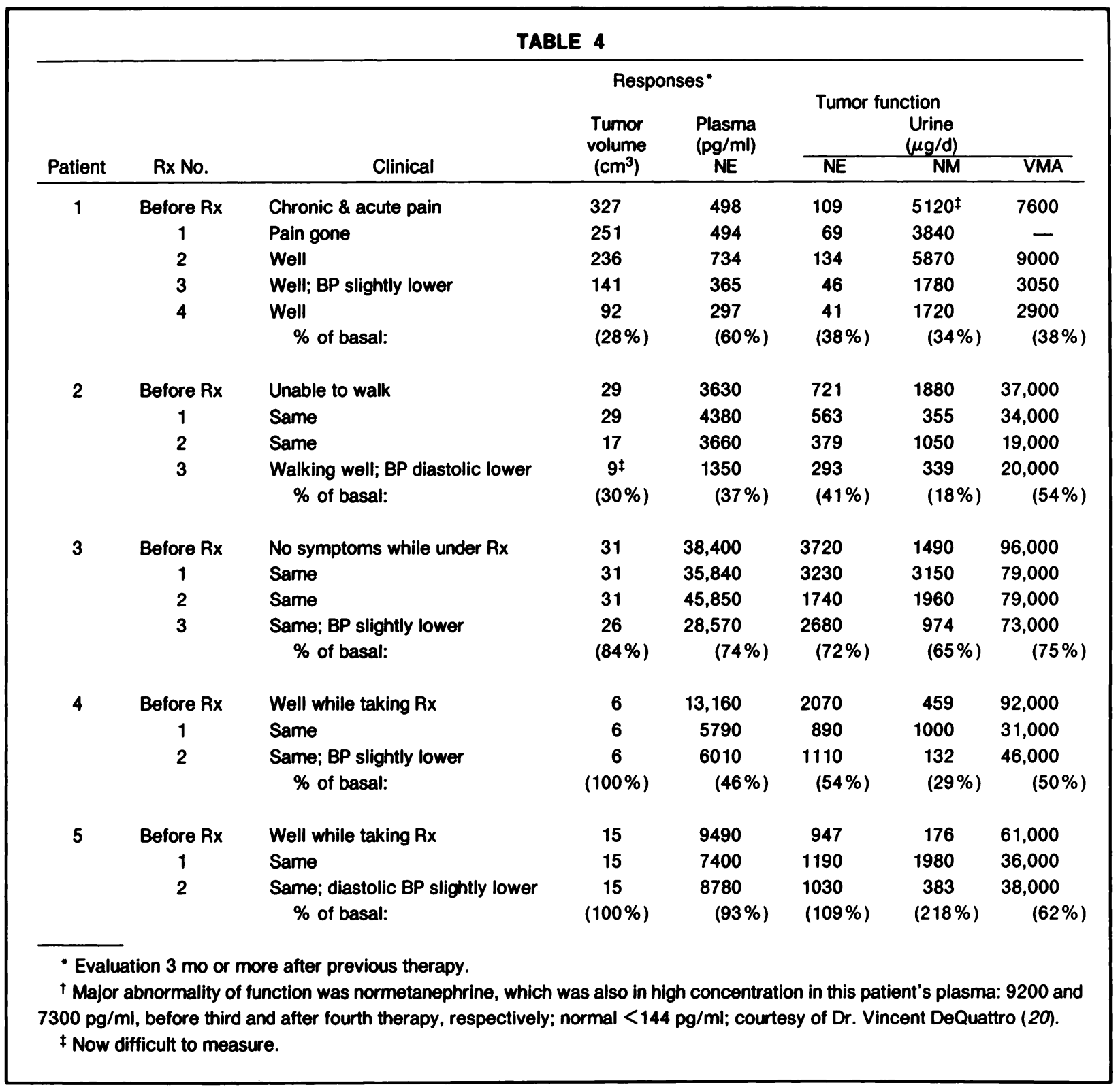

In contrast, in Patient 2 the uptake of I-131 MIBG by the liver tumors increased after her first treatment, an enhanced function that was unexplained, but one persisting after her second and third doses (Fig. 4). The rads delivered to this lady's cancer were relatively low at the outset, but they increased as uptake of I-131 MIBG rose and tumor size fell. As might be predicted from the radiation data, the clinical response in Patient 2 was delayed; it did not occur until after her third treatment (Table 4). As her plasma norepinephrine fell, her diastolic blood pressure was more often recorded at $80 \mathrm{~mm}$ of mercury. Metyrosine therapy has continued because her norepinephrine concentration has remained above normal.

Patients 3, 4, and 5 each received $270 \mathrm{mCi}$ or more of I-131 MIBG, but improvements in clinical status and tumor size have been modest or absent. In each of these patients there was a decline in the excretion of VMA, the largest component of catecholamine metabolism, but other indices of tumor function were altered less. The tumors of these three patients received lower cumulative doses than the tumors of Patients 1 and 2. However, the 8000 rad of the first treatment in Patient 1 was followed by beneficial effects (Tables 3 and 4). The cumulative rads imparted to the metastases of Patients 3 and 5 approached or exceeded $8000 \mathrm{rad}$, so factors other than total rad dose must play a role in determining the responses to the treatment. Uptakes of I-131 MIBG by the tumors of Patients 3, 4, and 5 remain high, indicating that additional treatments are possible.

Search for possible untoward effects of therapy. The patients were carefully observed for possible untoward 

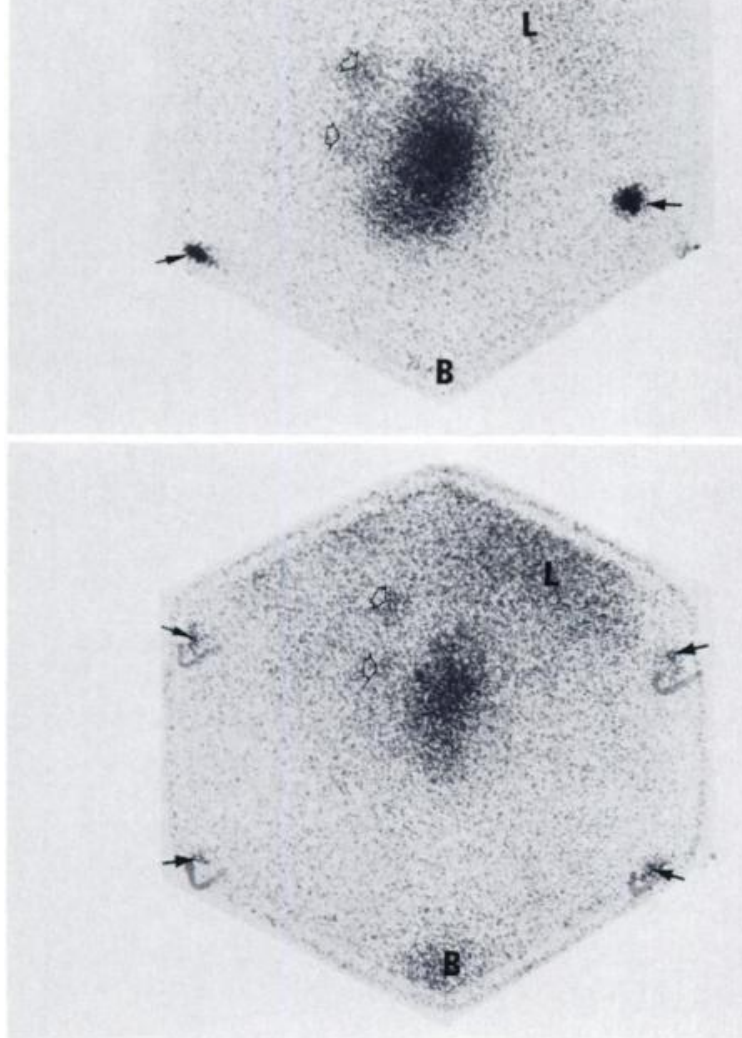

FIG. 2. Scintigrams of posterior abdomen, made 1 day after diagnostic dose of -131 MIBG, portraying largest tumor of Patient 1. Each image contains 100,000 counts; neither image was computerenhanced. Radioactivity in liver is denoted L, and in urinary bladder B. Upper: Before therapy (July 1981). Large open arrows indicate satellite concentrations of radioactivity that probably reflect metastases in lymph nodes. Small arrows point to markers on iliac crests. Lower: After three treatments with I-131 MIBG (May 1982). Uptake of radioactivity in largest tumor is clearly less in intensity and area than in upper. Metastases are also less distinct. Arrows point as indicated under upper. (Images after fourth treatment were similar but were in darker format so that visual comparison with upper is more difficult.)

effects. During the infusions of I-131 MIBG and immediately thereafter, neither symptoms nor change in vital signs occurred.

Because I-131 MIBG acts as an analog of norepinephrine and therefore would concentrate in adrenergic neurons, five tests of autonomic function were performed at each evaluation: (a) ratio of ECG R-R intervals after the Valsalva maneuver to $R-R$ intervals during the maneuver (21); (b) $R-R$ interval variation during deep breathing (22); (c) ratio of basal heart rate to that between the 15th and 30th beat after standing (23); (d) fall in systolic blood pressure immediately upon standing (24); and (e) rise in diastolic pressure during sustained hand grip (25). (The tests of autonomic function that use heart rates as indices relate particularly to the integrity of the vagus nerve, but since the responses to tests depend upon a balance between inhibitory and stimulatory forces, adrenergic neuron function is also assessed.) There was no deterioration in these functions after therapy. However, some abnormalities were noted before treatment, possibly caused by the actions of phenoxybenzamine, by high levels of circulating norepinephrine, or by damage to neurons from long prior exposure to large quantities of catecholamines. For example, Patient 1 consistently gave borderline results for four of the five tests, at times slightly abnormal and at other times barely normal. Impotence in Patient 1 was present at the outset and probably related to illness. Patients 3 and 4 reported diminished ejaculation while taking phenoxybenzamine, an aberration known to be caused by the drug.

No change in ECG patterns were recorded except in Patient 1 , who developed a small subendocardial infarct 1 mo after his fourth treatment (he had also suffered an infarct before therapy).

The radiopharmaceutical will concentrate in normal adrenal medullas, as shown in monkeys (26). In man, the adrenal medullas are usually not seen on scintigrams made after tracer doses of I-131 MIBG, probably because these organs and their fractional uptakes of the dose are small (27). Following the therapy doses, radioactivity in the region of the adrenal glands was portrayed in Patient 4, but the activity in metastatic deposits obscured the adrenal gland areas in other patients.

As noted above, the malignant pheochromocytomas probably synthesized relatively small quantities of epinephrine and these quantities obscured the epinephrine contributed by the patients' adrenal medullas. Changes in plasma levels and in urinary excretion rates of epinephrine tended to parallel those of norepinephrine (e.g., in Patient 2, plasma levels were $528 \mathrm{pg} / \mathrm{ml}$ before and $124 \mathrm{pg} / \mathrm{ml}$ after treatments, and urinary values were 198 $\mu \mathrm{g} /$ day before and $100 \mu \mathrm{g} /$ day after treatments). The decline in epinephrine may have been from effects on the tumor, or on both tumor and medullas. Thus, firm conclusions cannot be drawn for the effects of treatment on a patient's adrenal medulla.

Since the adrenal cortex surrounds the radioactivity accumulated in the medulla, function of the cortex was also assessed: plasma levels of cortisol and ACTH (measured in the morning) remained steady and normal.

The $50 \mathrm{mg}$ per day of Lugol's iodine was considered sufficient to block thyroidal uptake of nearly all free I-131 derived from I-131 MIBG (28). However, when the thyroid gland appeared on scintigrams after the first treatments with I-131 MIBG, the daily dose of iodide was increased to $150 \mathrm{mg}$ per day. Still, I-131 entered the thyroid in sufficient quantity to produce a scintigraphic image in each patient (nearby metastatic pheochromocytomas interfered with measurements of thyroid uptake 


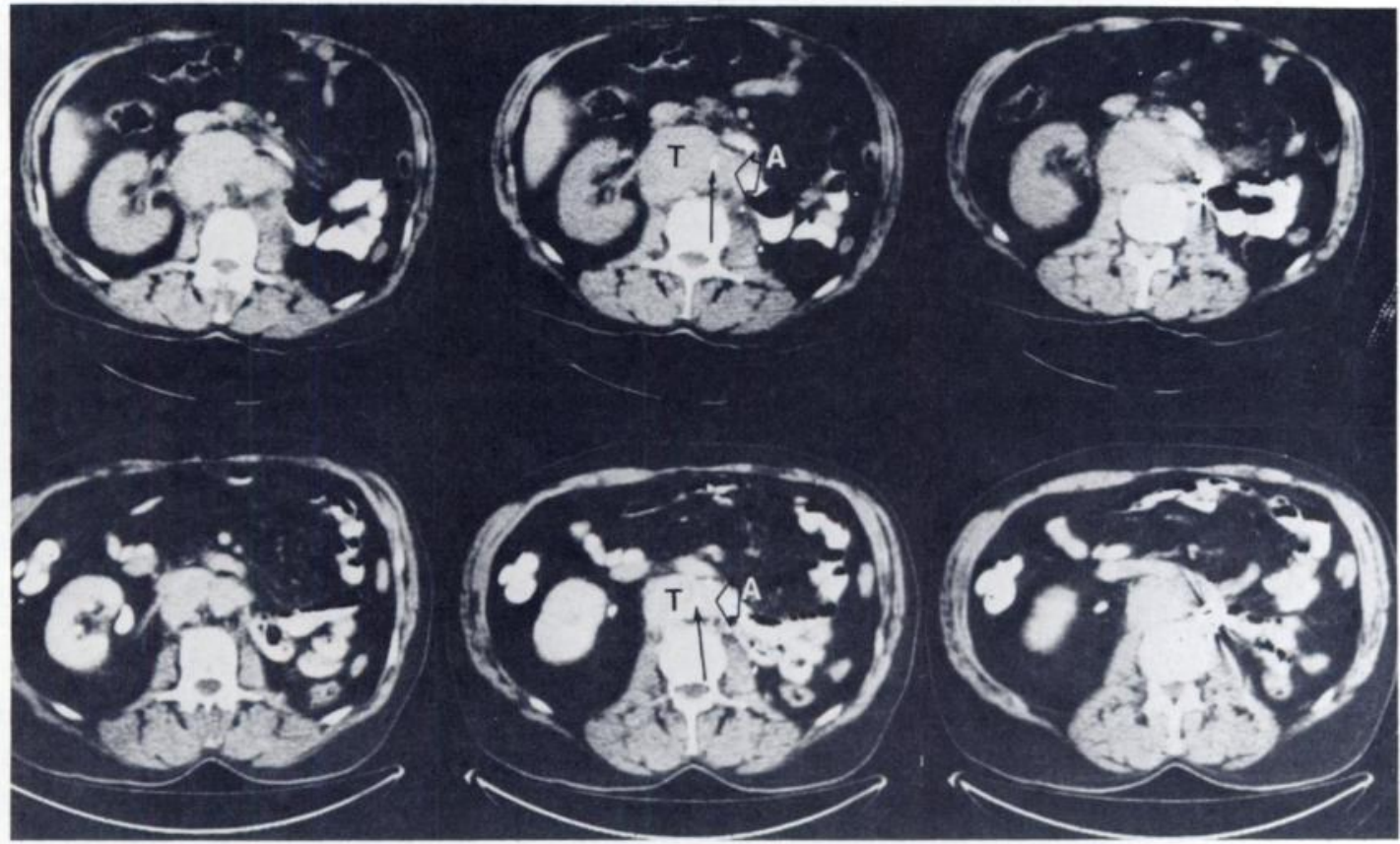

FIG. 3. TCT images of largest tumor (T) of Patient 1. Three successive 1-cm levels are shown to give rostral-caudal perspective. Upper three images were made before treatment, lower three images after four treatments with $1-131 \mathrm{MIBG}$. Smaller tumor size is evident. Small arrow indicates calcium deposit in aorta that was consistently seen at level of maximum tumor dimension. Letter A points to aorta.

of I-131, but as much as $100 \mu \mathrm{Ci}$ was sequestered by the thyroid of Patient 16 days after a 100-mCi treatment). Nevertheless, no palpable abnormalities have appeared in the thyroid glands, and serum concentrations of thyroxine, tri-iodothyronine and TSH have been consistently normal in all patients for up to $2 \mathrm{yr}$ following treatment.
Patient 5 developed a transient decline in his whiteblood-cell count after his second $(187 \mathrm{mCi})$ treatment: 4100 to 2900 to 3900 per $\mathrm{mm}^{3}$ over $4 \mathrm{mo}$. The platelet counts of Patient 2 declined successively after each treatment, but the thrombocytopenia did not reach dangerous levels (falling from a basal $405,000 / \mathrm{mm}^{3}$ to $169,000 / \mathrm{mm}^{3}$ after three treatments). Hematologic

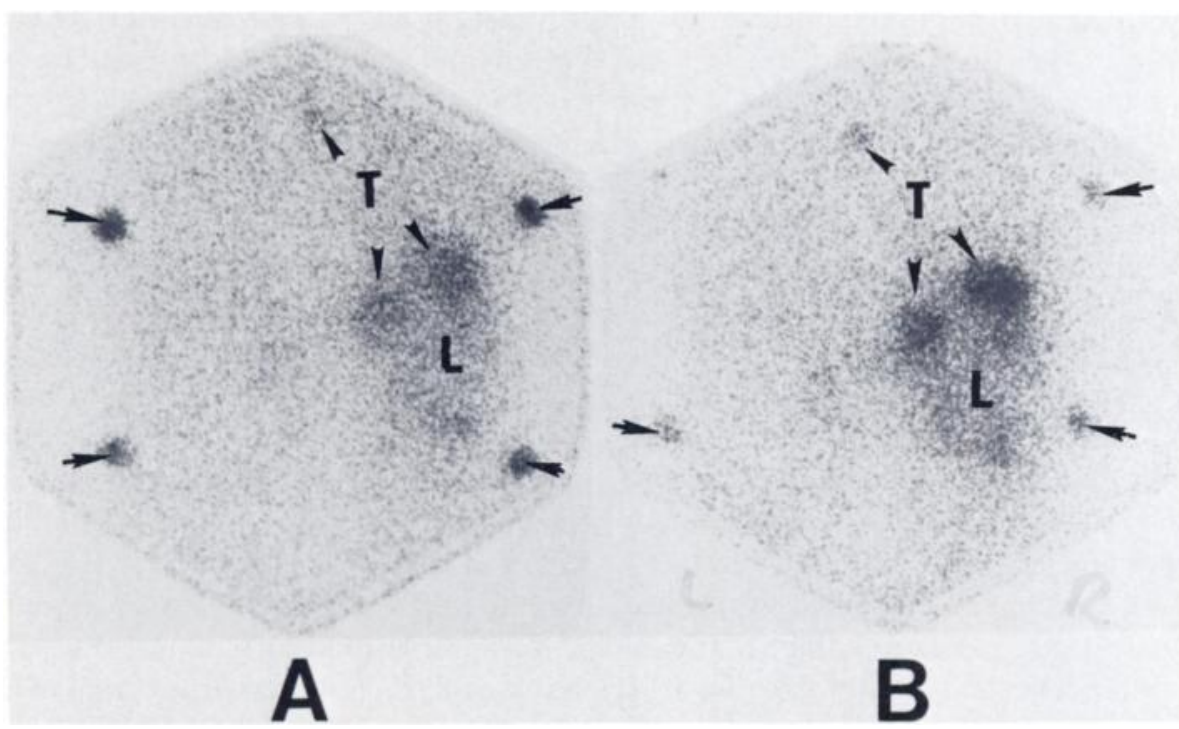

FIG. 4. Scintigrams of posterior abdomen, including liver (L), of Patient 2, made 2 days after injection of tracer doses of $1-131$ MIBG. Each image represents 100,000 counts; no enhancement was used by computer. A: Before treatment with L-131 MIBG (November 1981). This image is almost identical to one made 2 mo before. B: After three treatments with I-131 MIBG (October 1982). Note increase in radioactivity accumulated by two metastases $T$ in liver, compared with $A$. This increase was evident after first treatment, and persisted. Another metastasis was present in two thoracic vertebra (arrowhead); arrows are marked on patient's body. 
profiles were otherwise unchanged in all patients. Tests of renal and liver function were unaltered in each case.

Patient 1 developed herpes zoster 20 days after his second treatment, a disorder that was ameliorated by adenine arabinoside. Hair over a large skull tumor in Patient 3 was transiently lost after his largest treatment.

\section{DISCUSSION}

Following radiation therapy from external sources (x-ray, Co-60), pain caused by bone metastases from pheochromocytoma has often lessened or disappeared $(4,5,29-31)$. Objective changes in the malignant pheochromocytomas have been less frequent and of only a few months duration $(5,32,33)$. Since some malignant pheochromocytomas grow slowly, it is difficult to say that any treatment prolongs life, but remissions of many years have followed postoperative irradiation to tumor bed in rare instances $(34,35)$. However, because external radiation has so often ameliorated symptoms, it seems likely that this form of treatment constrains pheochromocytomas in some way. But doses of radiation delivered by an external source are limited to 5000 or fewer rads. Hence, the idea of treatment by I-131 MIBG, which might safely deliver larger doses of radiation from within, was compelling.

Two of our five patients were improved after treatments with I-131 MIBG; the improvements were in clinical status, size of tumors, and in secretion of hormones by the tumors, and have persisted for many months and to date. The clinical remissions were most striking: disability and pain disappeared from each patient, although Patient 2 still requires medication to control blood pressure. The decreases in both size and function of the tumors were substantial, but smaller still-functioning pheochromocytomas remain in each of these patients.

Differences between the two patients who attained benefit and the three who did not were several. Progression of tumor size over 1 to $2 \mathrm{yr}$ in Patients 1 and 2 may be an important difference. The numbers and volumes of tumors were observed to be stable for many years in Patient 3, were probably unchanged in Patient 4 over several years, and were apparently not increasing in Patient 5 for at least $1 \mathrm{yr}$. The lack of progression by the malignancy probably explained why symptoms related to tumor were modest and controlled by phenoxybenzamine in these latter patients. A higher rate of growth may cause more disability, but would also arise from a more rapid rate of cell division. More rapidly dividing cells should be more susceptible to the effects of irradiation. In fact, relief of pain by $x$-irradiation has most of ten occurred in expanding metastases of pheochromocytoma $(4,5,29-33)$.
The tumors of the two patients who were improved after I-131 MIBG treatments received more rads than the tumors of the other three patients. Irradiation exceeding 15,000 rads may be necessary to produce beneficial effects, but a high dose of radiation may not be the only determinant of response, since clinical and anatomic changes were noted in Patient 1 after the first treatment of about $8000 \mathrm{rad}$, a quantity of therapy ultimately exceeded in Patient 5.

In contrast to the soft-tissue locations of the neoplasms in Patients 1 and 2, bone lesions marked the metastatic patterns of Patients 3, 4, and 5. But, since Patient 3 harbored soft-tissue tumors that were as unchanged as his bone deposits after treatments, factors other than anatomic milieu may determine the radioresistance of pheochromocytomas.

Various combinations of chemotherapy have been administered to patients with malignant pheochromocytoma (3-7). Such medications have been given when the neoplasms are obviously progressing and causing symptoms. Subjective relief has been attained in perhaps half of the patients, and objective benefit in fewer $(4,6)$. And, except for a most unusual patient, remissions from chemotherapy have been partial and have lasted only a few months. Moreover, the chemotherapy programs almost invariably cause unpleasant side effects. One of the virtues of 1-131 therapy in the treatment of thyroid cancer has been the rarity of side effects $(36,37)$. The patients treated with I-131 MIBG also have had few untoward responses: transient leukopenia in Patient 5, temporary and circumscribed alopecia in Patient 3, and herpes zoster, a possible complication of radiation therapy, in Patient 1. Finally, the normal tissues likely to receive the most irradiation from I-131 MIBGadrenergic nerves, adrenal cortex, and thyroid glandhave manifested no change in their measurable functions. Although MIBG could exhibit tyramine-like actions, up to $5 \mathrm{mg}$ of this agent infused over $90 \mathrm{~min}$ causes no change in blood pressure.

In our experience, less than half of malignant pheochromocytomas concentrate high levels of I-131 MIBG. But, given sufficient uptake of I-131 MIBG, malignant pheochromocytomas should respond in a manner analogous to well-differentiated thyroid cancers treated with I-131. Both adrenergic and thyroid neoplasms exhibit indolent growth, and neither responds satisfactorily to chemotherapy $(3-5,36)$. Yet, functioning thyroid carcinomas have been destroyed by I-131 (38), and when the thyroid tumors secreted hormone sufficiently to cause hyperthyroidism, radiation doses above $10,000 \mathrm{rad}$ have regularly reduced the function to hypothyroidism (39-41). We believe that 20,000 or more rads via $I-131$ MIBG may achieve comparable results for malignant pheochromocytomas. Multiple treatments will be necessary to achieve this goal, but continued concentration of I-131 MIBG by tumors should make this possible. Our 
three patients whose pheochromocytomas have as yet been unresponsive to I-131 MIBG remain candidates for additional treatment.

Radionuclides in simple inorganic forms have been used for years in treatment. Recently, a publication reported therapy by I-131 as part of a large molecule: I-13I antiferritin antibody. Millicurie quantities of this radiolabeled agent apparently delivered sufficient radiation to diminish human hepatomas. Although this type of treatment was associated with marked toxicity, it heralds a new approach to cancer (42). We now demonstrate that a chemically synthesized molecule of complex structure, I-131 MIBG, can reduce malignant pheochromocytomas with little toxicity. This mode of therapy may find many applications when uptakes of other molecules by other neoplasms are exploited as routes for selectively delivering high levels of radiation.

\section{ACKNOWLEDGMENTS}

We are indebted to Drs. Allen Reisenfeld, Timothy Valk, Marc Frager, Jennifer Loggie, John Neeley, Edward Reasoner, P. K. Johnston, Timothy McHugh, and Richard Dorr for referral of patients and providing data on the patients before and after treatments. Drs. Gary Glazer and David Pennes gave expert interpretations of computed tomographic images. Ms. Laura Meyers and Mr. Steven Pitt were most helpful in processing data. We thank Ms. Vera Barton-Leitch and Karen Maki for preparing this manuscript.

This work supported by grants: NIAMDD (5 ROI AM 21477-03); American Cancer Society (PDT 182); NIAMDD 5 P60 AM 20575; Clinical Research Center (MOIRR42); and Nuclear Medicine Research Fund.

Brahm Shapiro is recipient of the Clinical Associate Physician Award.

\section{REFERENCES}

1. Robinson RG, DeQuattro V, Grushinin CM, et al: Childhood pheochromocytoma. Treatment with alpha methyl tyrosine for resistant hypertension. J Pediatr 91:143-147, 1977

2. Engelman K. SJoerdsma A: Chronic medical therapy for pheochromocytoma - a report of four cases. Ann Intern Med 61:229-241, 1964

3. Mornex R, Berthezene F, Peyrin L, et al: Pheochromocytomes malins. (special) Arch Mal Coeur 72:96-102, 1979

4. DRASIN H: Treatment of malignant pheochromocytoma. West J Med 128:106-111, 1978

5. SCOtT HW JR, ReYNOLdS V, Green N, et al: Clinical experience with malignant pheochromocytomas. Surg $G y$ necol Obstet 154:801-818, 1982

6. Scharf Y, NahiR AM, Better OS, et al: Prolonged survival in malignant pheochromocytoma of the Organ of Zuckerkandl with pharmaceutical treatment. Cancer 31: 746-750, 1973

7. HAMilton BPM, CheikH IE, Rivera LE: Attempted treatment of inoperable pheochromocytoma with streptozocin. Arch Intern Med 137:762-765, 1977

8. Sisson JC, Frager MS, VAlk TW, et al: Scintigraphic localization of pheochromocytoma. $N$ Engl J Med 305:12-7, 1981

9. Peuler JD, Johnson GA: Simultaneous single isotope radioenzymatic assay of plasma norepinephrine, epinephrine and dopamine. Life Sci 21:625-36, 1977

10. Nicholls MG, KıOWSKı W, ZWeifler AJ, et al: Plasma norepinephrine variations with dietary sodium intake. $\mathrm{Hy}$ pertension 2:29-32, 1980

11. VON EULER US, LISHAJKO F: The estimation of catecholamines in urine. Acta Physiol Scand 45:122-32, 1959

12. FREIER DT, HARRISON TS, DONAHUE SM, et al: Rigorous biochemical criteria for the diagnosis of pheochromocytoma. J Surg Res 14:177-180, 1973

13. Ciaranello RD: Regulation of phenylethanolamine Nmethyltransferase. Biochem Pharmacol 27:1895-1897, 1978

14. BuU NT, Nair G, Kuchel O, et al: The extraadrenal synthesis of epinephrine in rats: Possible involvement of dopamine sulfate. J Lab Clin Med 98:527-535, 1981

15. SwANSON DP, CAREY JE, BROWN LE, et al: Human absorbed dose calculations for iodine-131 and iodine-123 labeled meta-iodobenzylguanidine (mIBG): a potent myocardial and adrenal medulla imaging agent. In Proceedings of the Third International Symposium on Radiopharmaceutical Dosimetry. Oak Ridge, Tennessee, Oak Ridge Associated Universities, 1981, pp 213-224

16. Leichner PK, KLEIN JL, GARRISON JB, et al: Dosimetry of ${ }^{131}$ I-labeled anti-ferritin in hepatoma: a model for radioimmunoglobulin dosimetry. Int J Radiat Oncol Biol Phys 7:323-333, 1981

17. Thomas SR, Maxon HR, Kereiakes JG, et al: Quantitative external counting techniques enabling improved diagnostic and therapeutic decisions in patients with well-differentiated thyroid cancer. Radiology 122:731-737, 1977

18. MACEY DJ, MARShall R: Absolute quantitation of radiotracer uptake in the lungs using a gamma camera. $J \mathrm{Nucl}$ Med 23:731-735, 1982

19. MANGNER TJ, WU JL, WIELAND DM: Solid-phase exchange radioiodination of aryl iodides. Facilitation by ammonium sulfate. J Org Chem 47:1484-1488, 1982

20. Kobayashi K, Kolloch R, DeQuattro V, et al: Increased plasma and urinary normetanephrine in young patients with primary hypertension. Clin Sci 57: Suppl 5, 173s-176s, 1979

21. Ewing DJ, CAMpbell IW, Burt AA, et al: Vascular reflexes in diabetic autonomous neuropathy. Lancet 2:13541356, 1973

22. Page MM, Watkins PJ: The heart in diabetes: autonomic neuropathy and cardiomyopathy. Clin Endocrinol Metab 6:377-388, 1977

23. Clarke BF, Ewing DJ, Campbell IW: Diabetic autonomic neuropathy. Diabetologia 17:195-212, 1979

24. EWING DJ, IRving JB, KERR F, et al: Cardiovascular responses to sustained handgrip in normal subjects and in patients with diabetes mellitus: a test of autonomic function. Clin Sci Mol Med 46:295-306, 1974

25. Ewing DJ, Campbell IW, Murray A, et al: Immediate heart rate response to standing: sample test for autonomic neuropathy in diabetes. $\mathrm{Br}$ Med J 1:145-147, 1978

26. WIELAND DM, BROWN LE, TOBES MC, et al: Imaging the primate adrenal medulla with [ $\left.{ }^{123} I\right]$ and $\left[{ }^{131} I\right]$ metaiodobenzylguanidine. J Nucl Med 22:358-364, 1981

27. Nakajo M, Shapiro B, Copp J, et al: The normal and abnormal distribution of the adrenal medullary imaging agent ${ }^{131}$ I-metaiodobenzylguanidine ( ${ }^{131} \mathrm{I}-\mathrm{MIBG}$ ) in man: Evaluation by scintigraphy. $J$ Nucl Med: in press

28. Sternthal E, Lipworth L, Stanley B, et al: Suppression of thyroid radioiodine uptake by various doses of stable iodide. $N$ Engl J Med 303:1083-1088, 1980

29. JOSEPH L: Malignant pheochromocytoma of the Organ of 
Zuckerkandl with functioning metastases. $\mathrm{Br} J$ Urol 39: 221-225, 1967

30. SCHÖNEBECK J: Malignant pheochromocytoma. Scand J Urol Nephrol 3:64-68, 1969

31. HoLSTI LR: Malignant extra-adrenal phaeochromocytoma. Br J Radiol 37:944-947, 1964

32. Moloney GE, Cowdell RH, LewIS CL: Malignant phaeochromocytoma of the bladder. Br J Urol 38:461-470, 1966

33. Scharf Y, Ben ARIEh Y, et al: Orbital metastases from extra-adrenal pheochromocytoma. Am J Ophthalmol 69: 638-640, 1970

34. JAMES RE, BAKER HL JR, SCANLON PW: The roentgenologic aspects of metastatic pheochromocytoma. Am J Roentgenol 115:783-793, 1972

35. HIGGINS PMCR: Malignant phaeochromocytoma of the urinary bladder. Br J Urol 52:230, 1980

36. LEEPER RD, SHIMAOKA K: Treatment of metastatic thyroid cancer. Clin Endocrinol Metab 9:383-404, 1980

37. Sarkar SD, Beierwaltes WH, Gill SP, et al: Subsequent fertility and birth histories of children and adolescents treated with ${ }^{131}$ I for thyroid cancer. J Nucl Med 17:460-464, 1976

38. Beier waltes WH, Nishiyama RH, Thompson NW, et al: Survival time and "cure" in papillary and follicular thyroid carcinoma with distant metastases: Statistics following University of Michigan therapy. J Nucl Med 23:561-568, 1982

39. VAlenta L, LemarChand-BERAud T, NémeC J, et al: Metastatic thyroid carcinoma provoking hyperthyroidism with elevated circulating thyrostimulators. Am J Med 48:72-76, 1970

40. SNOw MH, Daves T, Smith BR, et al: Thyroid stimulating antibodies and metastatic carcinoma. Clin Endocrinol 10: 413-418, 1979

41. MCCONNON SK, von WeStaRp C, Mitchell RI: Follicular carcinoma of the thyroid with functioning metastases and clinical hyperthyroidism. Can Med Assoc J 112:724-727, 1975

42. ETtinger DS, ORder SE, Wharam MD, et al: Phase I-II study of isotopic immunoglobulin therapy for primary liver cancer. Cancer Treat Rep 66:289-297, 1982

\section{Central Chapter Society of Nuclear Medicine Annual Spring Meeting Adams Mark Hotel \\ Announcement and Call for Abstracts}

April 5-7, 1984

Indianapolis, Indiana

The Central Chapter of the Society of Nuclear Medicine will hold its Annual Spring Meeting April 5-7, 1984 at the Adams Mark Hotel in Indianapolis, Indiana.

The program is entitled "Cardio-Pulmonary: Current Diagnostic Techniques" and will provide 17 hours of Category 1 CME credit. VOICE credit will be available for technologists.

The faculty will include Drs. Philip Alderson, Richard Brashear, guest lecturers; and the following distinguished lecturers from the Central Chapter: Mr. Robert Anger, Drs. Carlos Bekerman, Manuel Brown, James Carey, J. Vinnoy Farris, John Freitas, Robert Henkin, Roger Hurwitz, Ervin Kaplan, Eugene Klatte, Suzanne Knoebel, Merle Loken, F. Michael Mullinix, Dan Pavel, Robert Polcyn, James Ryan, Henry Wellman, and Michael Zimmer. Commercial exhibits will be open April 5 and 6. Registration begins at 3:00 p.m., April 5.

Physicians, scientists, and technologists are encouraged to submit abstracts. Prizes of $\$ 250$ will be awarded for the best resident/basic scientist trainee and technologist abstracts.

A new feature this year will be the opportunity for presentation of "Tech Tips" in the program. Technologists may submit brief (less than 100 words) descriptions of improved or "neat" methods for performance of nuclear medicine procedures (with emphasis on cardio-pulmonary). These will be judged, published in the program, and a $\$ 50$ prize will be awarded for the best "Tech Tip."

Abstracts and/or Tech Tips must be prepared in final form for direct photoreproduction on the official abstract form. For forms and additional information contact:

Deborah A. Churan, Executive Director

Central Chapter, SNM

134 Lincoln Parkway

Crystal Lake, IL 60014

Tel: (815)459-6884

Deadline for submission of abstracts is March 7, 1984. 